\title{
Caminhos para a transdisciplinaridade como estratégia de pesquisa em saúde humana e meio ambiente
}

\section{Pathways to transdisciplinarity as a research strategy on human health and environment}

\author{
Zuleica Carmen Castilhos ${ }^{1,2}$ \\ ' Centro de Tecnologia Mineral, Laboratório de Especiação de Mercúrio Ambiental, Rio de Janeiro, Rio de Janeiro, Brasil \\ 2 Editora Associada da Rev Pan-Amaz Saúde, Ananindeua, Pará, Brasil
}

\begin{abstract}
É por certo a saúde coisa mui preciosa, a única merecedora de todas as nossas atenções e cuidados e de que a ela se sacrifiquem não somente todos os bens, mas a própria vida, porquanto na sua ausência a existência se nos torna pesada e porque sem ela o prazer, a sabedoria, a ciência, e até a virtude se turvam e se esvaem.
\end{abstract}

Michel Eyquem de Montaigne (1533-1592), sobre a importância da saúde para o ser humano'.

\begin{abstract}
A definição de saúde da Organização Mundial da Saúde (saúde é um estado de bem-estar, não apenas ausência de doença) ${ }^{2}$ amplia o conceito de ausência de doença, pois reconhece que a saúde é um produto das relações e interação dinâmica de múltiplos fatores, entre os quais, econômicos, sociais, ambientais, biológicos, genéticos, psíquicos, que se influenciam mutuamente. Portanto, estudar a contribuição relativa dos múltiplos fatores na promoção ou risco à saúde humana é um grande desafio. Na investigação de riscos à saúde humana por exposições a contaminantes ambientais, tal desafio tem sido enfrentado, tendo como estratégia estudos multidisciplinares. Por exemplo, pesquisas que objetivam avaliar os riscos à saúde humana e ao meio ambiente, por exposições ambientais a metais, em áreas de mineração, necessitam de equipes multidisciplinares, compostas por geólogos, engenheiros de minas, químicos, biólogos, médicos e epidemiologistas, entre outros. Recomenda-se que as equipes multidisciplinares sejam compostas por pesquisadores com reconhecimento técnico-científico em suas áreas específicas, de forma que todas as disciplinas envolvidas tenham sua importância fundamentada e reconhecida, para que não haja superação de determinada área em detrimento de outra e consequente perda do enfoque multidisciplinar ${ }^{3}$.
\end{abstract}

Tais abordagens, entretanto, se mostram assustadoras para alguns pesquisadores. Hochella Jr. ${ }^{4}$ elenca diversas dificuldades na execução e questiona o êxito de projetos interdisciplinares. Ao cabo da leitura, de fato, desencoraja os pesquisadores audaciosos que se interessam por tais abordagens. Sem negar tais percalços, é preciso reconhecer que nenhuma área do conhecimento, sozinha, ou mesmo várias áreas, separadamente, são eficientes na compreensão e resolução de problemas da vida real. Em especial na interface saúde e ambiente com vistas à qualidade de vida, pois os conceitos são ainda mais amplificados e, conforme Minayo ${ }^{5}$, " [...] incluem nossos desejos de felicidade, nossos parâmetros de direitos humanos, nosso empenho em ampliar as fronteiras dos direitos sociais e das condições de ser saudável e de promover a saúde". Assim, o objetivo das equipes multidisciplinares em projetos de pesquisa é não apenas dar conta, com qualidade, de cada uma das disciplinas que os compõem, mas, sobretudo, buscar estratégias para preencher os espaços existentes, que carecem de entendimento, entre as disciplinas, ou seja, são de natureza inter e transdisciplinar. Finalmente, ou ainda melhor, simultaneamente ou até mesmo antes de tudo, buscar, em conjunto com todas as partes interessadas, proposições de intervenções para a melhoria da saúde, ambiente e qualidade de vida.

Um bom exemplo de abordagem multidisciplinar aconteceu durante a execução do projeto internacional "Global Mercury Project - Removal of Barriers to the Introduction of Cleaner Artisanal Gold Mining and Extraction Technologies", no Brasil e na Indonésia. O objetivo geral do projeto foi avaliar a mineração artesanal de ouro como potencial fonte de contaminação de águas internacionais por mercúrio e, como objetivos específicos, avaliar a contaminação ambiental por mercúrio, seus efeitos sobre a saúde de garimpeiros de ouro e da população local não garimpeira, a contaminação de peixes por metilmercúrio e seus riscos à saúde humana e à sanidade dos peixes. Nesse projeto, participaram muitos profissionais de distintas áreas (engenharia de minas, geologia, geoquímica ambiental, geografia e cartografia, química, entre outras) ligadas à pequena mineração de ouro e seus impactos e riscos ambientais sobre solos, águas fluviais, sedimentos e peixes; e profissionais da área da saúde humana e ambiental (médicos, epidemiologistas, bioquímicos, médicos veterinários, e outros). No Brasil, esse projeto foi executado pelo Centro de Tecnologia Mineral (CETEM), Instituto Evandro Chagas e Faculdade de Veterinária da Universidade Federal Fluminense. Na Indonésia, foi executado pelo CETEM e pelo Instituto de Medicina Forense da Universidade de Munique (Alemanha). A abordagem integrada utilizada nesses estudos foi apresentada nas publicações de Castilhos et al. ${ }^{6,7}$, que têm sido bem acolhidas pela comunidade científica.

Outro exemplo é a Comunidade de Prática de EcoSaúde, que tem como base o enfoque ecossistêmico de saúde e proposta teórico-metodológica para sua execução. $O$ objetivo desse enfoque é5: 
[...] desenvolver novos conhecimentos sobre a relação saúde \& ambiente, em realidades concretas, de forma a permitir ações adequadas, apropriadas e saudáveis das pessoas que aí vivem. De tal forma que ciência e mundo da vida se unam na construção da qualidade de vida através de uma melhor gestão do ecossistema e da responsabilidade coletiva e individual sobre a saúde.

Por essa razão, a abordagem associa também as ciências sociais e busca inserir perspectivas da comunidade local e seus conhecimentos não científicos, os quais considera tão válidos quanto os resultados científicos com suas incertezas associadas. Dessa forma, inclui a escuta da população local sobre a sua perspectiva dos problemas, identifica líderes não formais, aborda questões de gênero e indica a necessidade da tradução de relatórios técnicos e de artigos científicos em informações acessíveis e úteis à sociedade, visando construir, de forma conjunta, alternativas de intervenções para a melhoria da qualidade de vida. Tais etapas têm sido cada vez mais incorporadas como requisitos básicos em projetos que adotem tal filosofia de trabalho. Essa abordagem tem reconhecido, como essencial e enriquecedora, a participação social. Minayo ${ }^{5}$ ressalta que o conceito de participação social deve ser mais amplo que o de participação comunitária, "[...] pois a investigação deve incluir os gestores públicos, os políticos, os empresários e todos os outros atores, individuais e coletivos, que têm a ver, direta ou indiretamente, com o problema". O objetivo é evitar que recaia sobre a parcela da população que sofre os problemas de saúde também a responsabilidade das soluções, as quais, em geral, envolvem aspectos técnico-científicos (cujo acesso deve ser facilitado, favorecendo a compreensão) e a tomada de decisão sobre políticas públicas. Assim, os pesquisadores ou técnicos têm um adequado papel de apoiadores no processo, sem pretender impor suas propostas de soluções para problemas porque, embora possam analisá-las tecnicamente, muitas vezes não compartilham dos problemas, pois pertencem a realidades diferentes.

A experiência de pesquisadores e instituições de pesquisas, no Brasil ou no exterior, nesse tipo de abordagem, ainda é incipiente ou reduzida. Por outro lado, não há uma única e infalível estratégia, mas a indicação de caminhos sólidos pelos quais se pode percorrer e que podem ser adaptados em função das especificidades locais. Por essa razão, tendem a crescer os exemplos de experiências em todo o mundo 8,9 .

Estratégias de estudos interdisciplinares e aplicação de perspectivas transdisciplinares, ainda que iniciais, foram também aplicadas em uma pesquisa de avaliação da contaminação ambiental por arsênio e exposição humana associada em área de mineração industrial de ouro $^{10}$. Além do envolvimento de todas as disciplinas importantes para esse tipo de estudo e já citadas anteriormente, a caracterização histórica e da dinâmica econômica e social, bem como a vivência da equipe no município, resultou na percepção da necessidade de ampliação da equipe com pesquisadores das áreas das ciências sociais, da antropologia e/ou sociologia, para a construção conjunta de alternativas de intervenção, em consonância com a perspectiva das diversas partes interessadas.

Os congressos EcoHealth e a revista EcoHealth são excelentes fontes de informação sobre a prática em projetos interdisciplinares em saúde. Organização internacional e congressos regulares têm-se mostrado ótimas fontes de discussões sobre tais temas. Outra área importante para estudos de exposição ambiental a contaminantes é a Geologia Médica. O Grupo de Pesquisas Núcleo de Avaliação de Risco Ambiental e Humano (NARAH) do Conselho Nacional de Desenvolvimento Científico e Tecnológico ( $\mathrm{CNPq}$ ) tem composição multidisciplinar e desenvolve abordagens interdisciplinares, buscando a transdisciplinaridade. Nessa experiência, a comunicação entre os pesquisadores é fundamental e pode ser promovida de diversas maneiras, presencial ou via internet. Os seminários realizados mostraram que, inicialmente, há pouca disposição de pesquisadores para assistir palestras sobre conceitos básicos de outras disciplinas com as quais não estão familiarizados. Entretanto, ao se darem conta das distintas perspectivas, estratégias de abordagem e técnicas das mais variadas áreas das ciências para abordar um mesmo assunto, essa barreira é superada. E, a partir daí, é possível haver profundo e diferenciado aprendizado, reconhecido por todos como uma oportunidade não apenas para o crescimento intelectual, mas principalmente para uma compreensão mais ampla dos problemas reais. Essa experiência proporciona uma visão de equidade entre os pesquisadores, o que permite convívio em uma atmosfera de admiração e confiança, essencial para que compartilhem seus conhecimentos no ambiente interdisciplinar. $E$, é nessa interação que são gerados os novos conhecimentos interdisciplinares. Segundo Maturana e Porksen ${ }^{11}$, a confiança é uma emoção produtiva na vida e, consequentemente, no ambiente de trabalho, enquanto que a competição impede a colaboração e as trocas mais importantes, não servindo de pano de fundo para o desenvolvimento da ciência. A participação social e o respeito pelo conhecimento não científico, como já mencionado, são igualmente essenciais.

A perseverança em estudos interdisciplinares, tendo como meta a transdisciplinaridade, parece um caminho seguro para a compreensão de temas complexos, como a saúde humana, meio ambiente e qualidade de vida, no contexto das exigências para um desenvolvimento sustentável. 


\section{REFERÊNCIAS}

1 Montaigne ME. Ensaios: da semelhança dos pais com os filhos. Tradução Sérgio Milliet. In: Minayo MCS. O desafio do conhecimento: pesquisa qualitativa em saúde. 14. ed. São Paulo: Hucitec; 2014. 407 p. (Saúde em debate; vol. 46).

2 World Health Organization. Constitution of the World Health Organization, 1946. Bull World Health Organ. 2002;80(12):983-4.

3 Minayo MC. Curso Comunidade de Prática em Ecosaúde. Teresópolis, RJ; 2004.

4 Hochella Jr. MF. So you want to form an interdisciplinary team? ...Good luck! Elements. 2006 Apr;2(2):67.

5 Minayo MCS. Enfoque ecossistêmico de saúde e qualidade de vida. In: Minayo MCS, Miranda AC, organizadores. Saúde e ambiente sustentável: estreitando nós. Rio de Janeiro: Fiocruz; 2002. p. 173-89.

6 Castilhos ZC, Rodrigues-Filho S, Rodrigues APC, Villas-Bôas RC, Shefa S, Veiga MM, et al. Mercury contamination in fish from gold mining areas in Indonesia and human health risk assessment. Sci. Total Environ. 2006;368(1):320-5.

7 Castilhos Z, Rodrigues-Filho S, Cesar R, Rodrigues AP, Villas-Bôas R, Jesus I, et al. Human exposure and risk assessment associated with mercury contamination in artisanal gold mining areas in the brazilian Amazon. Environ Sci Pollut Res. 2015;22(15):1 1255-64.

8 Charron DF, editor. Ecohealth research in practice: innovative applications of an ecosystem approach to health. Ottawa: International Development Research Centre; 2012. 282 p.

9 Távora R. Ecosaúde: experiências de pesquisa e práticas inovadoras para compreender os vínculos entre a saúde, os ecossistemas e a sociedade. Sustentabilidade em Debate. 2018;9(1):261-63.

10 Castilhos ZC, Capitani EM, Jesus I, Faial KF, Silva L, Egler S, et al. Arsenic in Paracatu: environmental and epidemiological assessment, political contextualization and risk communication strategies. In: 5th Biennial Conference of the Internacional Association for Ecology and Health- Ecohealth; 2015, Montreal.

11 Maturana Romesín H, Pörksen B. Del ser al hacer. Los orígenes del la biología del conocer. Santiago: JC Sáez; 2004. 